${ }^{1}$ Chronic Diseases Research Center, Endocrinology and Metabolism Population Sciences Institute, Tehran University of Medical Sciences, Tehran, Iran ${ }^{2}$ Non-communicable Diseases Research Center, Alborz University of Medical Sciences, Karaj, Iran ${ }^{3}$ Endocrinology and Metabolism Research Center, Endocrinology and Metabolism Clinical Sciences Institute, Tehran University of Medical Sciences, Tehran, Iran

${ }^{4}$ Department of Pediatrics, Child Growth and Development Research Center, Research Institute for Primordial Prevention of Non-communicable Disease, Isfahan University of Medical Sciences, Isfahan, Iran

${ }^{5}$ Development of Research \& Technology Center, Deputy of Research and Technology, Ministry of Health and Medical Education, Tehran, Iran ${ }^{6}$ Department of Epidemiology and Biostatistics, Shahid Beheshti University of Medical Science, Tehran, Iran ${ }^{7}$ Health Management and Economics Research Center, Iran University of Medical Sciences, Tehran, Iran ${ }^{8}$ Department of Pediatrics, Ahvaz Jundishapur University of Medical Sciences, Ahvaz, Iran ${ }^{9}$ Department of Medical Emergencies, Qom University of Medical Sciences, Qom, Iran ${ }^{10}$ Department of Basic and Clinical Research, Tehran Heart Center, Tehran University of Medical Sciences, Tehran, Iran

Correspondence to:

Mostafa Qorbani and Roya Kelishadi School of Medicine, Alborz University of Medical Sciences Baghestan, Boulevard, 31485/56, Karaj, Iran Child Growth and Development Research Center, Research Institute for Primordial Prevention of Non Communicable Disease, Isfahan University of Medical Sciences, Isfahan, Iran

mqorbani1379@yahoo.com

roya.kelishadi@gmail.com

Received on Sept/4/2019 Accepted on Dec/26/2019

\section{Economic inequality in prevalence of underweight and short stature in children and adolescents: the weight disorders survey of the CASPIAN-IV study}

\author{
Ramin Heshmat ${ }^{1}$ \\ https://orcid.org/0000-0002-8134-7940 \\ Mostafa Qorbani $i^{2,3}$ \\ https://orcid.org/0000-0002-3142-4960 \\ Nafiseh Mozafarian 4 \\ https:///orcid.org/0000-0002-8113-6721 \\ Shirin Djalalinia ${ }^{5}$ \\ https://orcid.org/0000-0002-9297-0834
}

Ali Sheidaei ${ }^{6}$

https://orcid.org/0000-0002-0480-5768

Morteza Mansourian ${ }^{7}$

https://orcid.org/0000-0002-2482-5424

Nastaran Hajizadeh 4

https://orcid. org/0000-0002-7950-8661

Mohammad Esmaeil Motlagh ${ }^{8}$

https://orcid.org/0000-0002-6101-548X

Hamid Asayesh ${ }^{9}$

https://orcid.org/0000-0001-7223-2642

Armita Mahdavi-Gorabi ${ }^{10}$

https://orcid.org/0000-0002-7872-9905

Roya Kelishadi ${ }^{4}$

https:///rcid. org/0000-0002-3362-4034

\section{ABSTRACT}

Objective: The aim of this study was to determine the determinants of socio-economic inequality in the prevalence of short stature and underweight in Iranian children and adolescents. Subjects and methods: This cross-sectional nationwide study was conducted on 36,486 participants, aged 6-18 years. This school-based surveillance (CASPIAN- IV) program and its complementary part on weight disorders evaluation was conducted in urban and rural areas of 30 provinces in Iran. In addition to physical examination, a validated questionnaire was completed from students and their parents. Socio-economic status (SES) was determined using principal component analysis, and was classified in quintile scale. Inequality in the prevalence of underweight and short stature was assessed using concentration (C) index and slop index of inequality (SII) by the Oaxaca-Blinder decomposition method. Results: The prevalence $(95 \% \mathrm{Cl})$ of underweight and short stature at national level was $10.89(10.55,11.23)$ and 4.15 $(3.94,4.38)$, respectively; it had a downtrend from the lowest to highest SES quintile. Furthermore, the value of $\mathrm{C}$ for underweight and short stature was negative, i.e. inequality was in favor of high SES groups. Moreover, the prevalence gap of underweight and short stature in the first and fifth quintiles of SES was $6.58 \%$ and $5.80 \%$, respectively. The highest proportion of this gap was explained by living area. In the multiple logistic model, odds of underweight and short stature were significantly lower in individuals with higher SES. Compared to boys, odds of underweight were decreased in girls, whereas odds of short stature were increased in them. Odds of underweight and short stature were increased in participants from rural areas than in urban areas. With increasing age, the odds of underweight and short stature decreased significantly. Conclusions: The results of this study showed that inequality in the prevalence of short stature and underweight was in favor of high SES groups. Moreover, living area was one of the most important determinants that explained this inequality. Therefore, this issue needs to be considered in health promotion policies. Arch Endocrinol Metab. 2020;64(5):548-58

\section{Keywords}

Underweight; short stature; inequality; socio-economic factors; Iran 


\section{INTRODUCTION}

$\mathrm{M}$ alnutrition is one of the most important health concerns in developing countries (1-3). Malnutrition in early life leads to physical growth retardation, underweight and short stature, associated with the frequent infections and resistance to treatment. In addition to reducing physical growth, emotional disorders, negative impact on learning and reducing the work efficiency may also be more common in children suffering from malnutrition. In the coming years, these children will not be able to reach age-appropriate mental and physical abilities $(4,5)$.

Weight status is influenced by multiple underlying factors like complicated gene-environment Interactions. Socioeconomic status (SES) includes social environment, social norms and media exposure, which can affect diet and body weight (3). According to WHO report, in developing countries, about 183 million children are underweight and 226 million are short stature (6). The overall prevalence of stunting, underweight, and wasting in Guatemala in 2006 was 34.4\%, 7.6\%, and $0.8 \%$, respectively (7). The prevalence of underweight, short stature, and wasting among Indianan children less than five years in 2013 was 33\%, 40\%, and $17 \%$, respectively (8). According to another cross-sectional study, underweight was $17.5 \%$ and the prevalence of short stature was 2.6\% in Iranian children (9).

Although the prevalence of child malnutrition in developing countries was reduced (10), SES inequality in malnutrition was observed especially in developing countries and some studies confirmed SES inequality (11-13). A cross-sectional study conducted on Guatemalan children showed that SES inequality in short stature is to the detriment of poor families (12). Another cross-sectional study conducted on Colombian children and adolescents showed that children and adolescents in poor families are five times more likely to be shorter than affluent families (13).

Moreover, in some studies, Oaxaca-Blinder decomposition method was used to determine the causes of inequality in malnutrition $(8,14-17)$. For example, a cross-sectional study conducted on Indian children less than five years demonstrated that malnutrition rate was higher in the urban poor families. The main factors contributing to the gap between the high and low SES groups in malnutrition were as follows: lower rate of using health care, the mothers' low BMI, and low parental educational levels (8). Another cross-sectional study performed in 2014 showed that there were SES inequalities in children's stunning. The $\mathrm{C}$ value of this inequality was negative, indicating that the inequality was in favor of the high SES group. In addition, the mothers' education was the most important factor contributing to the inequality in short stature (17).

There is limited evidence of inequality in short stature and underweight in children and adolescents, and most studies have been conducted on children under five years of age. Therefore, understanding the extent and the factors associated with short stature and underweight in children and adolescents is crucial. This study was aimed to assess SES inequalities and their associated factors in the prevalence of short stature and underweight in Iranian children and adolescents.

\section{SUBJECTS AND METHODS}

The present study was designed based on combined data of national survey of school-based surveillance system of Childhood and Adolescence Surveillance and PreventIon of Adult Non-communicable disease (CASPIAN-IV) study (18) and its complementary part on weight disorders evaluation $(19,20)$.

Through this investigation, 36,486 school students aged 10-18 years living in urban and rural areas of 30 provinces in Iran were randomly selected. Following the protocols of WHO-global school-based student health survey (GSHS-WHO),

Trained research experts followed all processes of examinations and inquiry with calibrated instruments. Information was recorded in the checklists and validated questionnaires for all participants (21). In order to assess the standards of quality of data in multicenter research, all levels of quality assurance were closely supervised and monitored by Data and Safety Monitoring Board (DSMB) of the project $(18,21,22)$.

\section{Definition of terms}

- Demographic information: All participants' demographic information including age, sex, residence area, family characteristics, family history (FH) of obesity, parental level of education, possessing a family private car, type of home etc., were gathered. Some complementary information on screen time (ST), physical activity (PA), and many other components of life styles were also questioned.

- Socioeconomic status (SES): Family SES was estimated using previous approach in the 
Progress in the International Reading Literacy Study (PIRLS) for Iran (23). By principle component analysis (PCA), variables of parents' education, parents' job, possessing private car, school type (public/private), type of home (private/rented) and having personal computer in home were combined as one main component of SES (24). This unique scale was categorized into 5 quintiles. Based on that, the first quintile was defined as a "lowest SES" and the fifth quintile as a "highest SES" groups.

- ST: The ST was calculated as the sum of the average daily hours spent onwatching television or video, as well as for leisure time use of personal computer (PC) or electronic games (EG). ST was asked separately for week days and weekends. To analyze correlates of ST, according to the international ST recommendations, ST was categorized into two groups: less than 2 hours per day (Low), and 2 hours per day or more (High) (25).

- PA: The recalls of activities in the prior week to the study were collected. The participants reported the weekly frequency of their leisure time PA outside the school. For PA, the two following questions were asked: 1) during the past week, on how many days were you physically active for overall 30 minutes per day? Response options were from 0 to 7 days; and 2) How much time do you spend in exercise class regularly in school per week? Responses ranged from 0 to 3 or more hours. PA less than two times per week was considered as mild, two to four times a week was considered as moderate and more than 4 hours a week was considered as vigorous $\mathrm{PA}(26)$.

\section{Measurements}

Weight was measured to the nearest $200 \mathrm{~g}$ in barefoot and lightly dressed condition. Body mass index (BMI) was calculated as weight in kilograms divided by height in meters squared $\left(\mathrm{m}^{2}\right)(18)$.

Underweight was defined as $\mathrm{BMI}<5^{\text {th }}$ percentile for age and sex based on the World Health Organization standard growth curves. Short stature was defined as height less than -2 standard deviation (SD) below the mean height for age and sex $(27,28)$.

After explanation of the study, participants and one of their parents were assured that their responses would remain anonymous and confidential. Participation in the study was voluntary and all of potential participants had the freedom to withdraw from the study at any time. Both written and verbal informed consent was obtained from the study participants and one of their parents respectively.

\section{Statistical analysis}

Continuous variables were presented as mean and SD. Prevalence of underweight and short stature was estimated with a 95\% confidence interval (CI). Association of independent variables with underweight and short stature was assessed using univariate and multivariate logistic regression analysis. The results of logistic regression analysis were presented as OR $(95 \% \mathrm{CI})$.

SES inequality in underweight and short stature was estimated by calculating the prevalence of underweight and short stature across quintiles of SES, the concentration index (C) and slop index of inequality (SII). To assess the association of weight disorders across SES quintiles, we used C which interpreted on the basis of the distribution of target variable versus SES distribution $(29,30)$. The $\mathrm{C}$ value was estimated using the following formula: $c=\frac{2}{n \mu} \sum_{i=1}^{n} n i R i-1$. Where $h i$ is the amount of each weight disorders for the $i-t h$ individual, $R i$ is the relative rank of the $i-$ th individual in the distribution of the SES variable and $\mu$ is the mean value of the weight disorders. The negative and positive values of $\mathrm{C}$ showed that inequality was in favor of high and low SES groups of the SES, respectively (29).

Decomposition of the gap in weight disorders between the first and fifth quintiles of SES was investigated using the counterfactual decomposition method $(31,32)$. This method divides the gap between the means of an interested outcome variable into two components. The "explained" (endowment) component arises because of differences in groups' characteristics, such as differences in age, sex or other characteristics of two groups, and an 'unexplained' (coefficient) component is extracted from the differential effects of these characteristics.

Statistical measures were assessed using survey data analysis methods in the STATA software (version 11.1, Stata Corporation, College Station, TX, USA). $P<$ 0.05 was considered as statistically significant. Missing data were imputed using Amelia package version 1.7.3 in $\mathrm{R}$ statistical package. 


\section{RESULTS}

Overall, 36,486 students participated in this survey (response rate: 91.3\%). average age of students was 12.14 (3.36) years and no statistically significant differences were found between males and females. Considering the sex $49.21 \%$ and regarding the resident area $74.23 \%$ of participants were aligned to females and urban areas resident, respectively.

Appendix 1 presents the socioeconomic inequality in the prevalence of underweight in Iranian children and adolescents at national and provincial levels. By increasing SES quintiles, values of these variables followed trends with different slopes in various provinces.

The national estimation of prevalence of underweight was $10.89 \%$ (95\% CI: $10.55,11.23$ ) with descending changing from $[14.61 \%(13.76,15.49)]$ to $[8.02 \%(7.38,8.72)]$ according to SES categories. At provincial level, the highest and the lowest prevalence of underweight were $[23.21 \%(20.94,25.66)]$ and $[4.87 \%(3.19,7.37)]$, respectively. Considering the SII values, at national level $[-0.01(-0.10,0.07)]$ absolute difference in prevalence of underweight between the bottom and top of the socioeconomic groups showed the descending trends.

At national level, negative $\mathrm{C}$ index (-0.12) indicated that inequality was in favor of high SES groups.

Short stature with different patterns among provinces had a national estimation of 4.15[3.94, 4.38 ] with nearly descending changes along with the SES categories. At provincial level, the highest and the lowest prevalence rates were $8.69[7.23,10.39]$ and $1.20[0.70,2.06]$ respectively. Considering the SII values, at national level $0.06[-0.01,0.15]$ the absolute difference in prevalence of short stature between the bottom and top of the socioeconomic groups showed ascending trends. Negative $\mathrm{C}$ index at national level $(-0.25)$ suggested that inequality was in favor of high SES groups (Appendix 2).

Figure 1 shows the $\mathrm{C}$ index of underweight and short statue at provincial levels. Figure 2 shows the association of $\mathrm{C}$ index with prevalence of underweight and short stature. Based on the results, C Index could be used to explain $0.08 \%$ of variation of variable of underweight and $0.05 \%$ of variable of short stature.

The gap between the low and high SES groups for prevalence of underweight and short stature was $6.58 \%$ and $5.80 \%$ respectively. In the explained component living area was seen to make highest contribution to the gap between the two SES groups for prevalence of underweight and short stature (Table 1).

In multivariate logistic regression analysis, odds of underweight and short stature were significantly lower in individual with higher SES $(\mathrm{p}<0.001)$. Compared to males, odds of underweight were decreased in females [OR: 0.86 (95\% CI: 0.80, 0.93)], and odds of short stature were increased in them [OR: $1.30(95 \%$ CI: $1.16,1.46)](\mathrm{p}<0.001)$. Participant from rural areas compared to those who were from urban areas had increased odds of underweight [OR: $1.22(95 \%$ CI: $1.12,1.32)$ ] and short stature [OR: $1.35(95 \%$ CI: $1.20,1.53)](\mathrm{p}<0.001)$. Each year increment in age decrease the odds of underweight [OR: 0.97 (95\% CI: $0.96,0.98)$ ] and short stature [OR: $0.91(95 \%$ CI: $0.89,0.93)](\mathrm{p}<0.001)($ Table 2$)$.
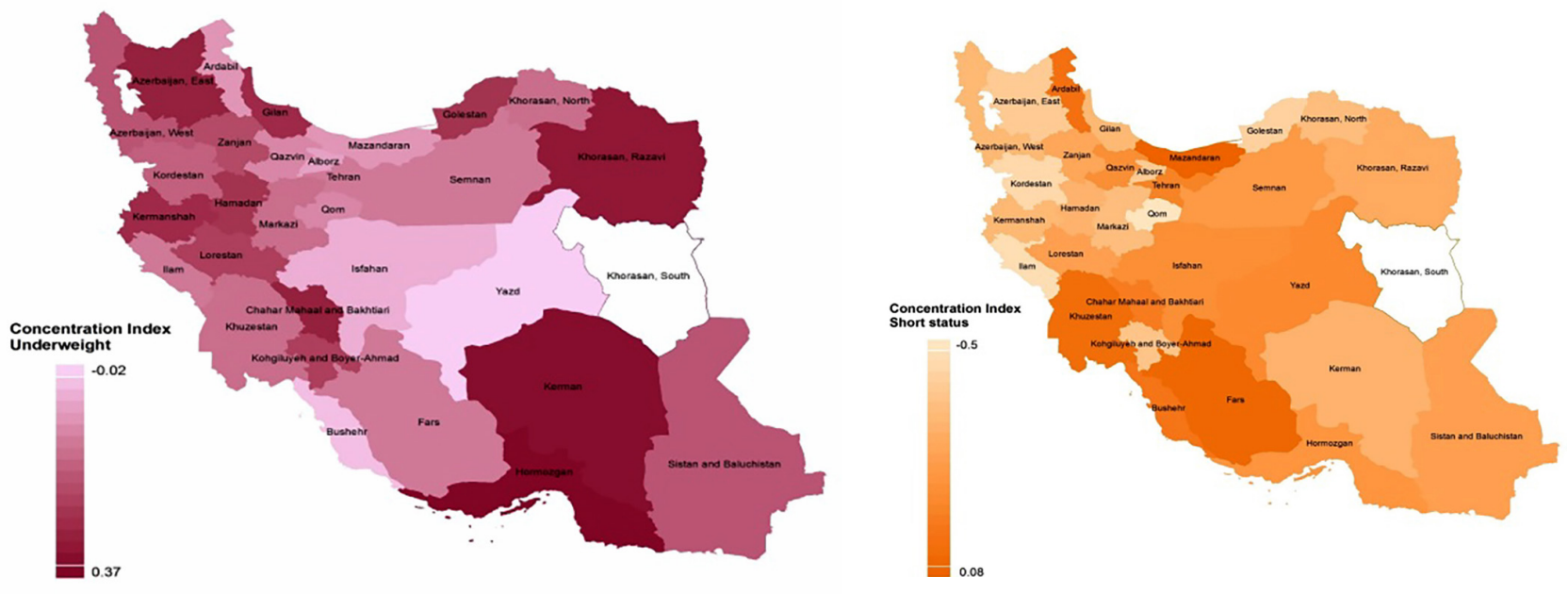

Figure 1. The $C$ index of underweight and short statue at provincial levels in Iranian children and adolescents: the CASPIAN IV study. 

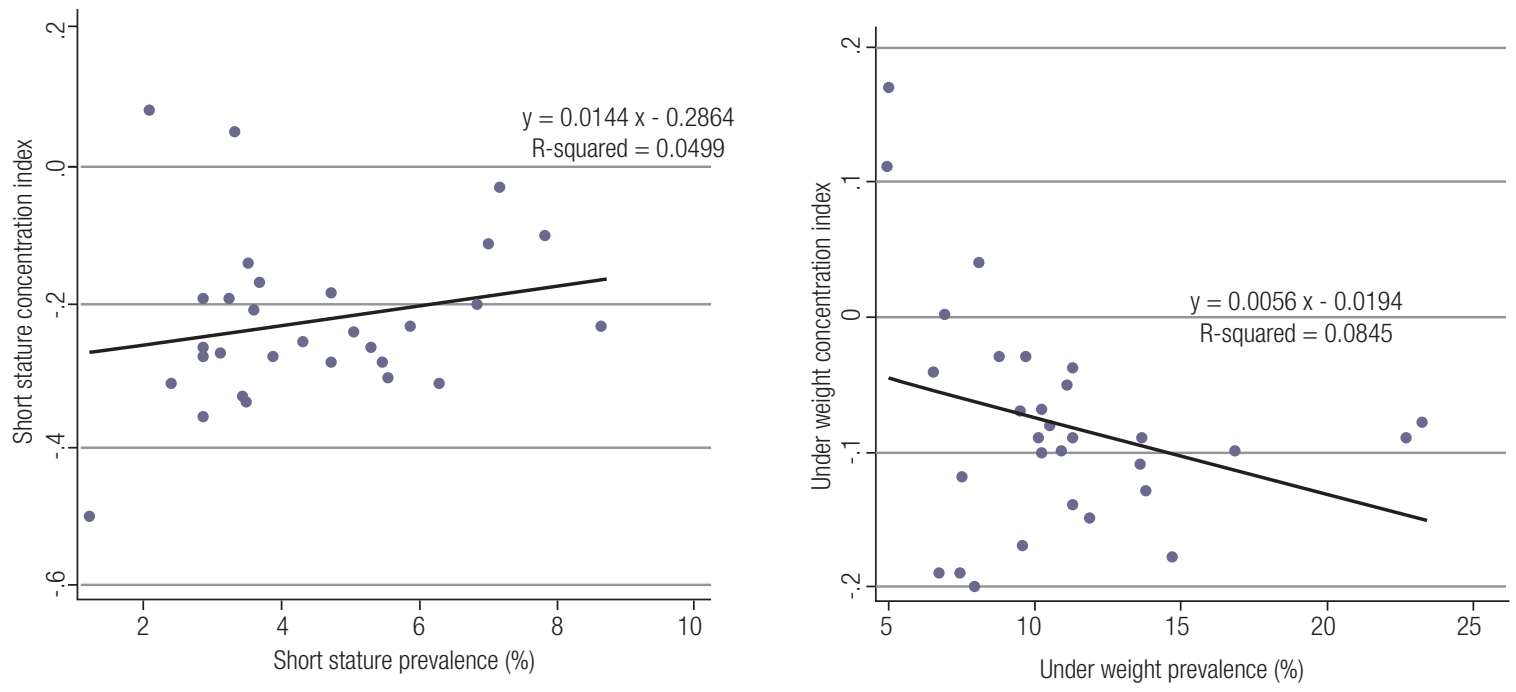

Figure 2. The association of $C$ index with prevalence of underweight and short stature in Iranian children and adolescents: the CASPIAN IV study.

Table 1. Decomposition of the gap in prevalence of underweight and short stature between the first and fifth quintiles of socioeconomic status in Iran

\begin{tabular}{|c|c|c|c|c|c|c|c|c|}
\hline \multirow[b]{3}{*}{ Prevalence in first quintile of SES } & \multicolumn{4}{|c|}{ Underweight } & \multicolumn{4}{|c|}{ Short stature } \\
\hline & \multirow{2}{*}{$\begin{array}{c}\text { Prediction (\%) } \\
14.68\end{array}$} & \multicolumn{2}{|c|}{$95 \% \mathrm{Cl}$} & \multirow{2}{*}{$\begin{array}{c}\mathbf{P} \\
<0.001\end{array}$} & \multirow{2}{*}{$\begin{array}{c}\text { Prediction (\%) } \\
8.53\end{array}$} & \multicolumn{2}{|c|}{$95 \% \mathrm{CI}$} & \multirow{2}{*}{$\begin{array}{c}\mathbf{P} \\
<0.001\end{array}$} \\
\hline & & 13.79 & 15.57 & & & 7.83 & 9.24 & \\
\hline Prevalence in fifth quintile of SES & 8.09 & 7.41 & 8.77 & $<0.001$ & 2.74 & 2.33 & 3.14 & $<0.001$ \\
\hline Differences (Total gap) & 6.59 & 5.47 & 7.72 & $<0.001$ & 5.80 & 4.99 & 6.61 & $<0.001$ \\
\hline \multicolumn{9}{|l|}{ Due to endowments (explained) } \\
\hline Physical activity & -0.03 & -0.07 & 0.01 & 0.177 & -0.05 & -0.10 & 0.00 & 0.055 \\
\hline Sex & -0.01 & -0.04 & 0.01 & 0.355 & 0.01 & -0.01 & 0.03 & 0.458 \\
\hline Screen time & 0.16 & 0.00 & 0.33 & 0.048 & 0.43 & 0.32 & 0.53 & $<0.001$ \\
\hline Region & 0.96 & 0.35 & 1.58 & 0.002 & 1.01 & 0.54 & 1.47 & $<0.001$ \\
\hline FH of obesity & 0.20 & 0.11 & 0.29 & $<0.001$ & - & - & - & - \\
\hline Age & -0.05 & -0.10 & -0.01 & 0.027 & -0.05 & -0.10 & -0.01 & 0.019 \\
\hline Subtotal & 1.23 & 0.58 & 1.89 & $<0.001$ & 1.34 & 0.85 & 1.83 & $<0.001$ \\
\hline \multicolumn{9}{|l|}{ Due to coefficients (unexplained) } \\
\hline Physical activity & 0.07 & -0.39 & 0.53 & 0.761 & -0.46 & -0.84 & -0.07 & 0.019 \\
\hline Sex & -5.42 & -8.82 & -2.03 & 0.002 & 2.19 & -0.24 & 4.62 & 0.077 \\
\hline Screen time & -0.81 & -1.49 & -0.13 & 0.019 & -1.13 & -1.53 & -0.73 & $<0.001$ \\
\hline Region & 0.65 & -3.32 & 4.62 & 0.749 & 1.21 & -1.51 & 3.93 & 0.382 \\
\hline FH of obesity & -0.77 & -1.55 & 0.01 & 0.053 & - & - & - & - \\
\hline Age & 4.24 & 0.24 & 8.24 & 0.038 & -4.03 & -7.07 & -0.99 & 0.009 \\
\hline Subtotal & 5.36 & 4.10 & 6.62 & $<0.001$ & 4.46 & 3.58 & 5.34 & $<0.001$ \\
\hline
\end{tabular}

SES: socioeconomic status: SES is an economic and sociological combined total measure of a person's work experience and of an individual's or family's economic and social position in relation to others. FH: family history: past occurrences (of a medical or mental health condition) in family members or past incidences (of a type of behavior) by family members. 
Table 2. Association of independent variables with underweight and short stature in multivariate logistic regression

\begin{tabular}{|c|c|c|c|c|c|}
\hline \multirow{2}{*}{ Variables } & & \multicolumn{2}{|c|}{ Underweight } & \multicolumn{2}{|c|}{ Short stature } \\
\hline & & Crude OR (95\% Cl) & Adjusted OR (95\% Cl) & Crude OR (95\% Cl) & Adjusted OR (95\% Cl) \\
\hline \multirow[t]{5}{*}{ SES } & (Q1) & & & & \\
\hline & Q2 & $0.80(0.72,0.89)^{\star}$ & $0.83(0.75,0.92)^{\star}$ & $0.47(0.40,0.55)^{\star}$ & $0.52(0.45,0.61)^{\star}$ \\
\hline & Q3 & $0.71(0.64,0.79)^{\star}$ & $0.76(0.68,0.84)^{*}$ & $0.31(0.26,0.37)^{\star}$ & $0.39(0.32,0.46)^{\star}$ \\
\hline & Q4 & $0.57(0.51,0.64)^{\star}$ & $0.62(0.55,0.70)^{\star}$ & $0.29(0.24,0.34)^{*}$ & $0.36(0.29,0.43)^{\star}$ \\
\hline & Q5 & $0.51(0.45,0.57)^{\star}$ & $0.56(0.50,0.64)^{\star}$ & $0.30(0.25,0.36)^{\star}$ & $0.36(0.30,0.44)^{\star}$ \\
\hline \multirow[t]{3}{*}{ Physical activity } & Low & & & & \\
\hline & Moderate & $1.01(0.94,1.09)$ & $0.95(0.88,1.04)$ & $1.07(.94,1.21)$ & $1.03(.90,1.18)$ \\
\hline & High & $1.10(1.00,1.22)$ & $1.03(0.92,1.15)$ & $2.22(1.94,2.56)^{\star}$ & $1.88(1.61,2.20)^{\star}$ \\
\hline \multirow[t]{2}{*}{ Sex } & Boy & & & & \\
\hline & Girl & $0.86(0.81,0.92)^{\star}$ & $0.86(0.80,0.93)^{\star}$ & $1.15(1.03,1.28)^{\star}$ & $1.30(1.16,1.46)^{\star}$ \\
\hline \multirow[t]{2}{*}{ Screen time } & $\leq 2 \mathrm{~h}$ & & & & \\
\hline & $>2 h$ & $0.82(0.76,0.88)^{\star}$ & $0.91(0.84,0.98)^{*}$ & $0.42(0.36,0.48)^{\star}$ & $0.52(0.44,0.60)^{*}$ \\
\hline \multirow[t]{2}{*}{ Region } & Urban & & & & \\
\hline & Rural & $1.48(1.38,1.59)^{\star}$ & $1.22(1.12,1.32)^{\star}$ & $2.14(1.92,2.38)^{\star}$ & $1.35(1.20,1.53)^{\star}$ \\
\hline \multirow[t]{2}{*}{ FH of obesity } & (No) & & & & \\
\hline & Yes & $0.81(0.75,0.88)^{\star}$ & $0.80(0.74,0.87)^{\star}$ & - & - \\
\hline Age & (year) & $0.96(0.95,0.97)^{\star}$ & $0.97(0.96,0.98)^{*}$ & $0.88(0.87,0.90)^{*}$ & $0.91(0.89,0.93)^{\star}$ \\
\hline
\end{tabular}

SES: socioeconomic status: SES is an economic and sociological combined total measure of a person's work experience and of an individual's or family's economic and social position in relation to others. FH: family history: past occurrences (of a medical or mental health condition) in family members or past incidences (of a type of behavior) by family members.

*Statistically significant.

\section{DISCUSSION}

This national study showed that the prevalence of underweight and short stature, with different patterns in the provinces and national estimation, was 10.89 $[10.55,11.23]$ and $4.15[3.94,4.38]$, respectively. Moreover, SES inequalities were documented in the prevalence of underweight and short stature in Iranian children and adolescents. The value of $\mathrm{C}$ index for underweight and short stature was negative, showing that the inequality was to the detriment of poor families. The frequency of differences in underweight and short stature between the first and fifth quintiles was 6.59\% and $5.80 \%$, respectively. It indicated higher prevalence of short stature and underweight in the lowest SES quintiles. Moreover, the results showed that the rate of short stature in low SES classes was about 3 times more than the upper class, which should be considered by health policy makers, in designing future intervention programs to reduce this inequality.
Regarding SES inequality in malnutrition, the results of present study were consistent with previous studies. A study conducted on children under 5 years old in 47 developing countries on demonstrated that SES inequalities in malnutrition were observed in developing countries. Furthermore, it was shown that the inequality in short stature was higher in Latin America and the Caribbean region, according to the $\mathrm{C}$ index (11). Some studies in developing countries reported that the $\mathrm{C}$ index of inequality for prevalence of short stature was negative, meaning that inequality was in favor of high SES groups and the prevalence of short stature was higher in children in poor families $(8,12-13,17,33)$.

Across-sectional study (2012) in Columbia showed that children and adolescents in poor families were five times more likely to be stunt than affluent families. Over one-third of socioeconomic inequality in short stature is due to care practices and family characteristics, especially maternal education (13). 
The results of a longitudinal study in Brazil (2010), showed that during a period of 33 years (1974-2007) the prevalence of short stature was decreased from $37.1 \%$ to $7.1 \%$ and SES inequality in stunted children had decreased over time. In this study, living area plays a main role in underweight and short stature inequalities, which may be due to food security and access to healthy food and clean water or sanitary facilities such as cultural beliefs and level of health awareness and access to health care is different in rural areas than in cities (33).

Possibly, health conditions, such as the use of water sanitation in urban areas is better than that in rural areas and these hygienic conditions in urban areas have a positive impact on the prevention of infectious diseases and therefore affect children's nutritional status; Moreover, urban families are less likely to face food insecurity and more ability to provide adequate care for children, including health services. The evidence showed that, in general, children in urban areas have a better nutritional status than those in rural areas $(34,35)$.

Providing the same living conditions in urban and rural areas might be a significant contributor to reducing inequalities. So it is better to provide sanitary facilities in rural areas, such as clean water, health services and health care, education interventions to raise mothers 'nutrition and health awareness, and struggle against culturally wrong nutritional habits. Another suggestion is to create favorable educational conditions for girls in rural areas which can lead to healthier future generations. Studies have always concluded that the mother's education is of a great importance for health, nutrition and child's survival (36-38).Also, recognizing the social and cultural issues related to family understanding of the nutritional needs for food distribution within the family and performing comprehensive interventions (such as cultural, economic, social and nutritional education), especially in rural areas seems necessary to prevent malnutrition.

Our findings about the significant effect of ST on SES inequality, are in line with the previous studies $(39,40)$. In the present study, the higher SES groups had more ST. It was also shown that the risk of underweight and short stature reduced as the ST increased. Some review studies showed that watching TV was correlated with food habits in children or young adults (4l-43) and also it was shown that there was a positive correlation between the time spending on watching TV and energy intake $(42,44,45)$ which can lead to weight disorders.
In the present study, in multivariate model, low SES, male gender, living in rural area and increment in age was associated significantly with higher prevalence of underweight and short stature. This finding is concordant with previous studies $(7,46-50)$. A previous study conducted in Iran showed that the prevalence of underweight in boys was higher than that in girls and malnutrition was correlated with mother's occupation, parents' education and the number of children (47). A cross-sectional study conducted in Guatemala showed that educational status, child and family care are the most influential factors on short stature (7).

\section{Strengths and limitations}

The limitations of this study were as follows: the crosssectional nature of the study does not allow us to conclude causal inference and using self-reported data. One of the main strengths of this study was a large sample size which let us to assess the SES inequality at national and provincial levels. Moreover, in this study, the standard and validated questionnaire of $\mathrm{WHO}$ was used.

In conclusion, the results of the present study showed that inequality in prevalence of short stature and underweight was in favor of high SES groups and living area was one of the most important determinants that explained this inequality. To minimize inequality, policy makers should attend for this hidden part, and take appropriate policies to deal with this issue. In addition, more attention should be given to the lower SES levels to take necessary measures to reduce the gap between upper and lower SES groups.

Acknowledgments: the authors would like to express their deep gratitude to the members of CASPIAN project team and their families, as well as participants of the study, that without their cooperation, it would be impossible to conduct this study.

Ethical approval: this study was approved by the Research and Ethics Council of Isfahan University of Medical. Sciences (code: 194049).

Disclosure: no potential conflict of interest relevant to this article was reported.

\section{REFERENCES}

1. World Health Organization. The world health report 2002: reducing risks, promoting healthy life. Geneva: World Health Organization; 2002. 
2. Schofield C, Ashworth A. Why have mortality rates for severe malnutrition remained so high? Bull World Health Organ. 1996;74(2):223-9.

3. Rahmanian $M$, Kelishadi $R$, Qorbani $M$, Motlagh ME, Shafiee $\mathrm{G}$, Aminaee T, et al. Dual burden of body weight among Iranian children and adolescents in 2003 and 2010: the CASPIAN-III study. Arch Med Sci. 2014;10(1):96-103.

4. Norgan N. Long-term physiological and economic consequences of growth retardation in children and adolescents. Proc Nutr Soc. 2000;59(02):245-56.

5. Jafari-Adli S, Qorbani M, Heshmat R, Ranjbar SH, Taheri $\mathrm{E}$, Motlagh ME, et al. Association of short stature with life satisfaction and self-rated health in children and adolescents: the CASPIAN-IV study. J Pediatr Endocr Metab. 2016;29(11):1299-306.

6. World Health Organization. World Health Statistics Report. Geneva: World Health Organization; 2011.

7. Sereebutra P, Solomons N, Aliyu MH, Jolly PE. Socio-demographic and environmental predictors of childhood stunting in rural Guatemala. Nutr Res. 2006;26(2):65-70.

8. Kumar A, Singh A. Decomposing the gap in childhood undernutrition between poor and non-poor in urban India, 200506 PLoS One. 2013;8(5):e64972.

9. Bahreynian M, Motlagh ME, Qorbani M, Heshmat R, Ardalan G, Kelishadi R. Prevalence of Growth Disorders in a Nationally Representative Sample of Iranian Adolescents According to Socioeconomic Status: The CASPIAN-III Study. Pediatr Neonatol. 2015;56(4):242-7.

10. United Nations Children's Fund WHO. The World Bank. UNICEF WHO-World Bank: Joint Child Malnutrition Estimates. Geneva: WHO; 2012.

11. Van de Poel E, Hosseinpoor AR, Speybroeck N, Van Ourti T, Vega J. Socioeconomic inequality in malnutrition in developing countries. Bull World Health Organ. 2008;86(4):282-91.

12. Lee J, Houser RF, Must A, de Fulladolsa PP, Bermudez OI. Socioeconomic disparities and the familial coexistence of child stunting and maternal overweight in Guatemala. Econ Hum Biol. 2012;10(3):232-40.

13. Garcia S, Sarmiento OL, Forde I, Velasco T. Socio-economic inequalities in malnutrition among children and adolescents in Colombia: the role of individual-, household-and communitylevel characteristics. Public Health Nutr. 2013;16(9):1703-18.

14. Joe W, Mishra US, Navaneetham K. Inequalities in childhood malnutrition in India: some evidence on group disparities. J Hum Dev Capabil. 2009;10(3):417-39.

15. Van de Poel E, Speybroeck N. Decomposing malnutrition inequalities between Scheduled Castes and Tribes and the remaining Indian population. Ethn Health. 2009;14(3):271-87.

16. Wagstaff A, Van Doorslaer E, Watanabe N. On decomposing the causes of health sector inequalities with an application to malnutrition inequalities in Vietnam. $J$ Econometr. 2003;112(1):207-23.

17. Emamian $\mathrm{MH}$, Fateh $\mathrm{M}$, Gorgani $\mathrm{N}$, Fotouhi A. Mother's education is the most important factor in socio-economic inequality of child stunting in Iran. Public health Nutr. 2014;17(9):2010-5.

18. Kelishadi R, Ardalan G, Qorbani M, Ataie-Jafari A, Bahreynian M, Taslimi M, et al. Methodology and early findings of the fourth survey of childhood and adolescence surveillance and prevention of adult non-communicable disease in Iran: The CASPIAN-IV study. Int J Prev Med. 2013;4(12):1451-60.

19. Kelishadi R, Majdzadeh R, Motlagh ME, Heshmat R, Aminaee T, Ardalan G, et al. Development and evaluation of a questionnaire for assessment of determinants of weight disorders among children and adolescents: The Caspian-IV study. Int J Prev Med. 2012;3(10):699-705.
20. Kelishadi R, Motlagh ME, Bahreynian M, Gharavi MJ, Kabir $\mathrm{K}$, Ardalan G, et al. Methodology and early findings of the assessment of determinants of weight disorders among Iranian children and adolescents: The childhood and adolescence surveillance and prevention of adult Noncommunicable DiseaseIV study. Int J Prev Med. 2015;6:77.

21. Organización Panamericana de la Salud. Organización Mundial de la Salud. Global School-based Student Health Survey. Washington, DC; 2008.

22. Shrewsbury V, Wardle J. Socioeconomic status and adiposity in childhood: a systematic review of cross-sectional studies 19902005. Obesity (Silver Spring). 2008;16(2):275-84.

23. Martin MO, Mullis IV, Kennedy AM. Progress in International Reading Literacy Study (PIRLS): PIRLS 2006 Technical Report: ERIC. International Association for the Evaluation of Educational Achievement; 2007.

24. Abdi H, Williams LJ. Principal component analysis. Wiley Interdisciplinary Reviews: Computational Statistics. 2010;2(4):433-59.

25. American Academy of Pediatrics: Children, adolescents, and television. Pediatrics. 2001;107(2):423-6.

26. Kelishadi R, Ardalan G, Gheiratmand R, Gouya MM, Razaghi EM, Delavari A, et al. Association of physical activity and dietary behaviours in relation to the body mass index in a national sample of Iranian children and adolescents: CASPIAN Study. Bull World Health Organ. 2007;85(1):19-26.

27. WHO Multicentre Growth Reference Study Group. WHO Child Growth Standards based on length/height, weight and age. Acta Paediatr Suppl. 2006;450:76-85.

28. Baya Botti AM PCEA, Vasquez Monllor P, Kolsteren $P$. Anthropometry of height, weight, arm, wrist, abdominal circumference and body mass index, for Bolivian adolescents 12 to 18 years: Bolivian adolescent percentile values from the MESA study. Nutr Hosp. 2009;24(3):304-11.

29. Koolman X, van Doorslaer E. On the interpretation of a concentration index of inequality. Health Econ. 2004;13(7):649-56.

30. Shaw M, Galobardes B, Lawlor D, Lynch J, Wheeler B, DaveySmith G. The handbook of inequality and socioeconomic position: concepts and measures. Bristol, UK: The Policy Press; 2007.

31. Emamian M, Zeraati H, Majdzadeh R, Shariati M, Hashemi H, Jafarzadehpur $\mathrm{E}$, et al. Economic inequality in presenting near vision acuity in a middle-aged population: a Blinder-Oaxaca decomposition. Br J Ophthalmol. 2013;97(9):1100-3.

32. Borooah VK, lyer $\mathrm{S}$. The decomposition of inter-group differences in a logit model: Extending the Oaxaca-Blinder approach with an application to school enrolment in India. J Econ Soc Meas. 2005;30(4):279-93.

33. Monteiro CA, Benicio MHDA, Conde WL, Konno S, Lovadino AL, Barros AJ, et al. Narrowing socioeconomic inequality in child stunting: the Brazilian experience, 1974-2007. Bull World Health Organ. 2010;88(4):305-11.

34. Ruel MT, Garrett JL, Morris SS, Maxwell D, Oshaug A, Engle P, et al. Urban challenges to food and nutrition security: a review of food security, health, and caregiving in the cities. Washington, DC: IFPRI; 1998.

35. Von Braun J. Urban food insecurity and malnutrition in developing countries:Trends, policies, and research implications. Intl Food Policy Res Inst. 1993.

36. Armar-Klemesu M, Ruel MT, Maxwell DG, Levin CE, Morris SS. Poor maternal schooling is the main constraint to good child care practices in Accra. J Nutr. 2000;130(6):1597-607.

37. Team CS. Underlying and proximate determinants of child health: The Cebu Longitudinal Health and Nutrition Study. Am J Epidemiol. 1991;133(2):185-201. 
38. Cleland JG, Van Ginneken JK. Maternal education and child survival in developing countries: the search for pathways of influence. Social Sci Med. 1988;27(12):1357-68.

39. Tremblay MS, LeBlanc AG, Kho ME, Saunders TJ, Larouche R, Colley RC, et al. Systematic review of sedentary behaviour and health indicators in school-aged children and youth. Int J Behav Nutr Phys Act. 2011;8:98.

40. Prentice-Dunn H, Prentice-Dunn S. Physical activity, sedentary behavior, and childhood obesity: a review of cross-sectional studies. Psychol Health Med. 2012;17(3):255-73.

41 Ford C, Ward D, White M. Television viewing associated with adverse dietary outcomes in children ages 2-6. Obes Rev. 2012;13(12):1139-47.

42 Pearson N, Biddle SJ. Sedentary behavior and dietary intake in children, adolescents, and adults: a systematic review. Am J Prev Med. 2011;41(2):178-88.

43. Sleddens EF, Kroeze W, Kohl LF, Bolten LM, Velema E, Kaspers PJ, et al. Determinants of dietary behavior among youth: an umbrella review. Int J Behav Nutr Phys Act. 2015;12:7.

44. Wiecha JL, Peterson KE, Ludwig DS, Kim J, Sobol A, Gortmaker SL. When children eat what they watch: impact of television viewing on dietary intake in youth. Arch Pediatr Adolesc Med. 2006;160(4):436-42.

45. Temple JL, Giacomelli AM, Kent KM, Roemmich JN, Epstein LH. Television watching increases motivated responding for food and energy intake in children. Am J Clin Nutr. 2007;85(2):355-61.

46. Djalalinia S, Qorbani M, Peykari N, Kelishadi R. Health impacts of obesity. Pak J Med Sci. 2015;31(1):239-42.

47. Bahreynian M, Kelishadi R, Qorbani M, Motlagh ME, Kasaeian A, Ardalan G, et al. Weight disorders and anthropometric indices according to socioeconomic status of living place in Iranian children and adolescents: The CASPIAN-IV study. J Res Med Sci. $2015 ; 20(5): 440-53$.

48. Heer DM. Effect of number, order, and spacing of siblings on child and adult outcomes: An overview of current research. Soc Biol. 1986;33(1-2):1-4.

49. Kariuki F, Monari J, Kibui M, Mwirichia M, Zani K, Tetei M, et al. Prevalence and risk factors ofmalnutrition. J Natl Inst Public Health. 2002;51(1):44-50.

50. Shah SM, Selwyn BJ, Luby S, Merchant A, Bano R. Prevalence and correlates of stunting among children in rural Pakistan. Pediatr Int. 2003;45(1):49-53. 


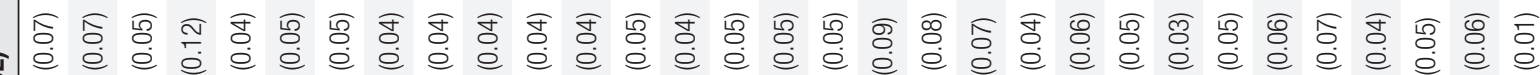

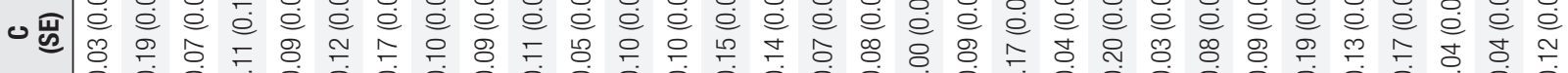
然

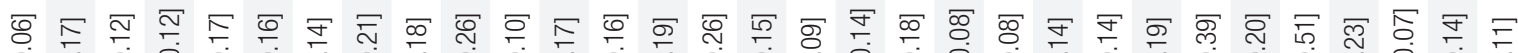

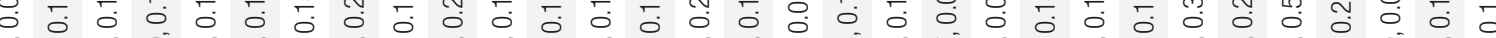
o

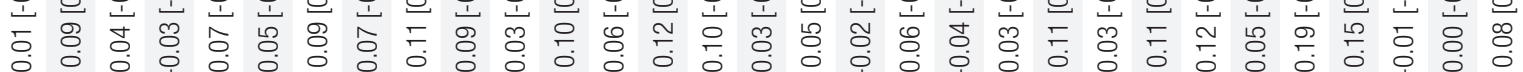

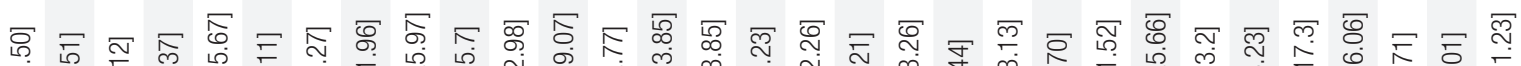

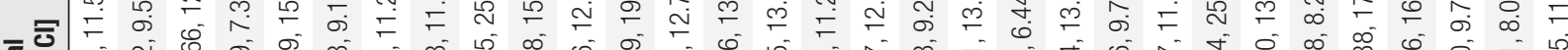

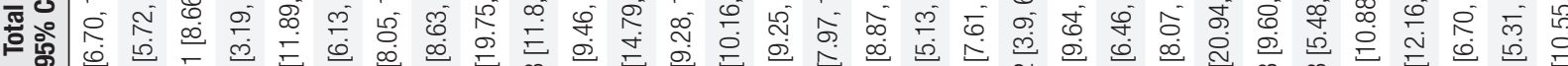
他 চ

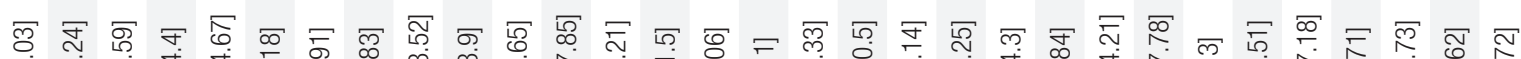

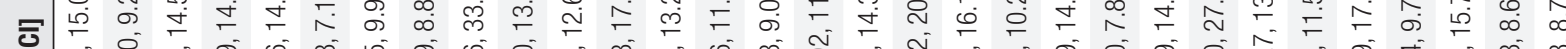
đ广

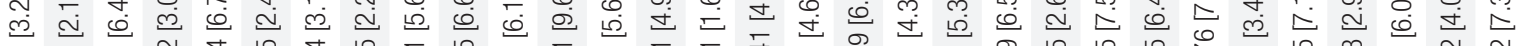
芹

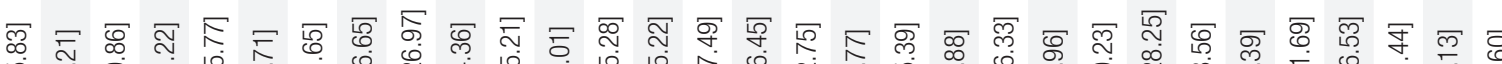

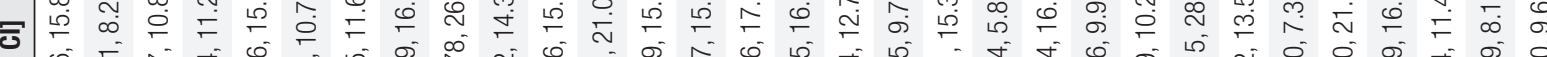
垔

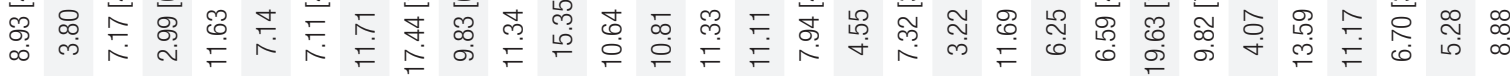

অ

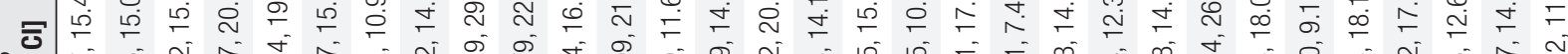

ஆำ

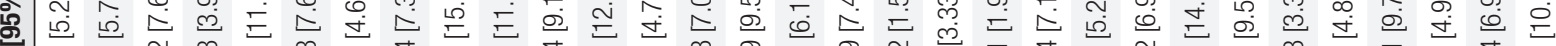

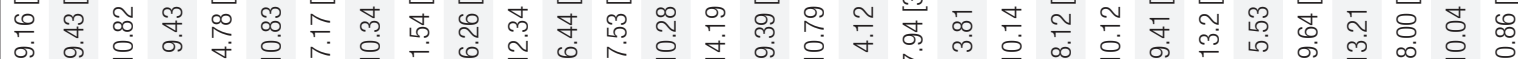

屌

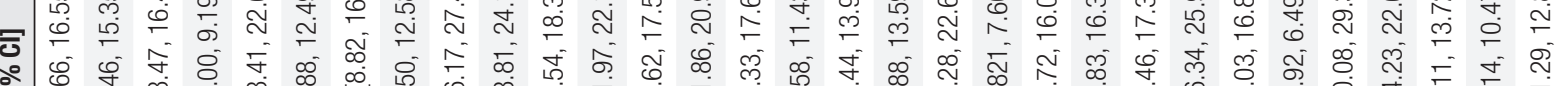
年

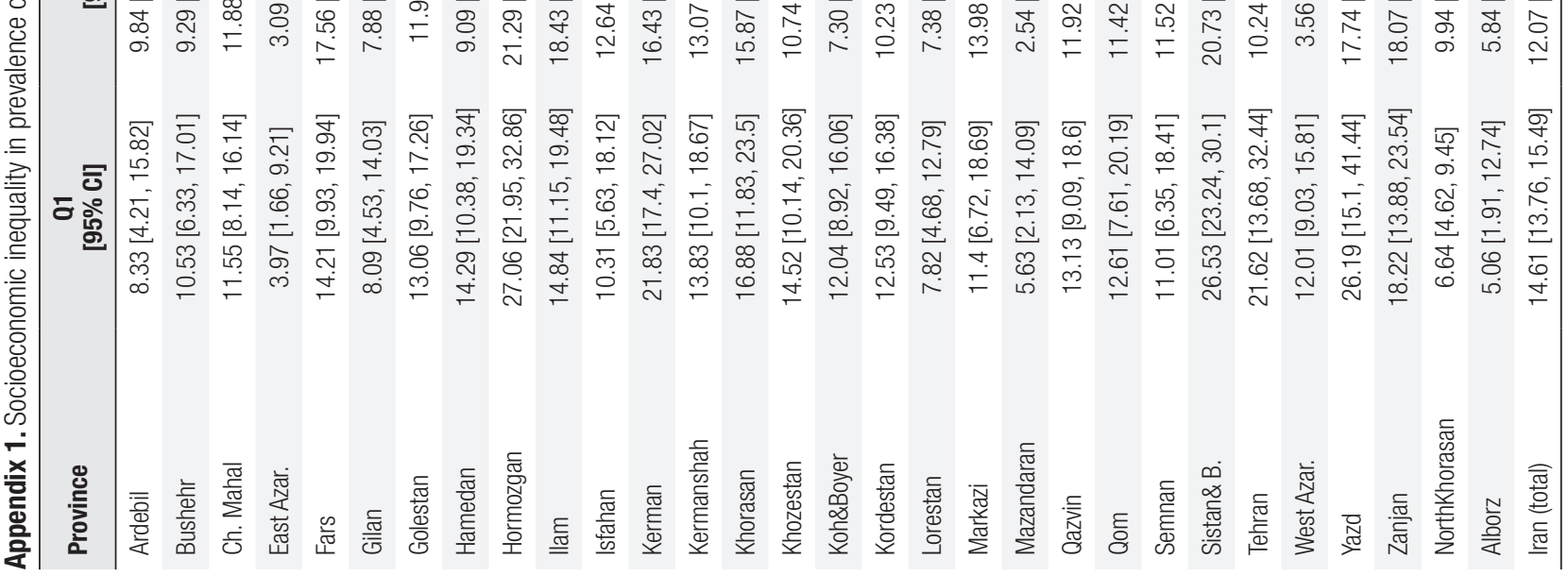




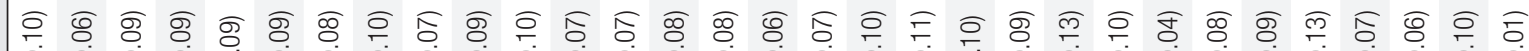

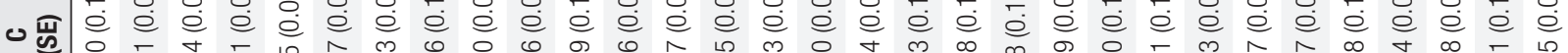
辰

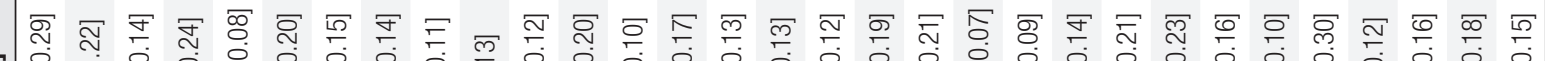

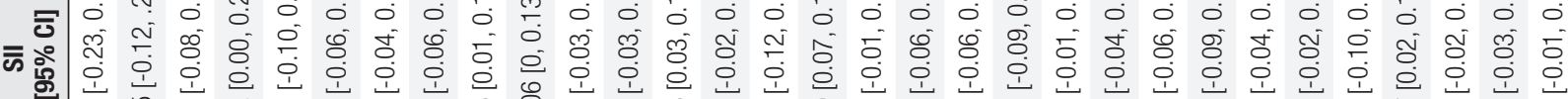

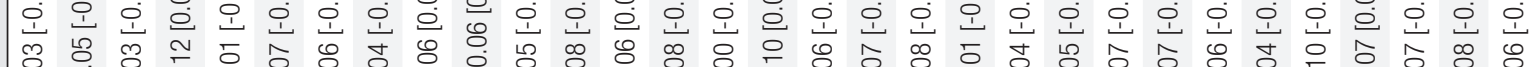

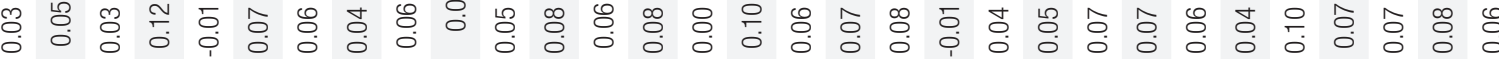

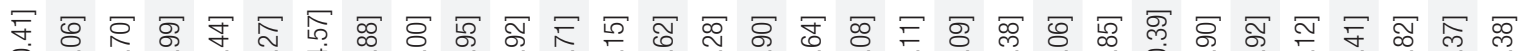

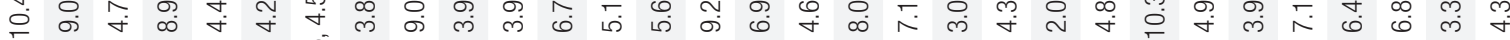

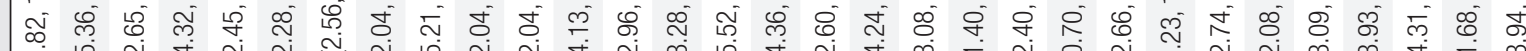

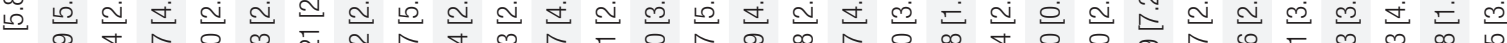

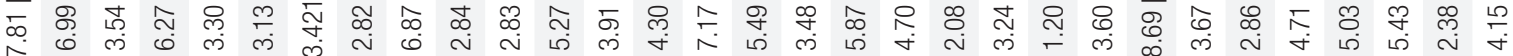

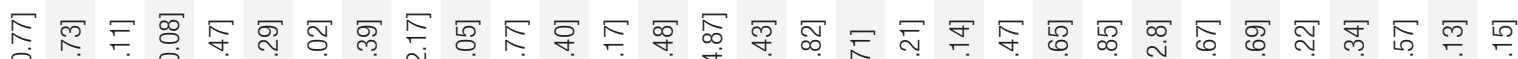

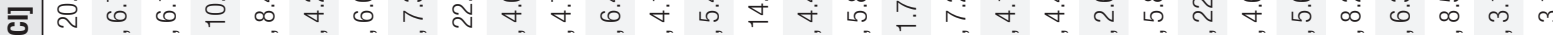

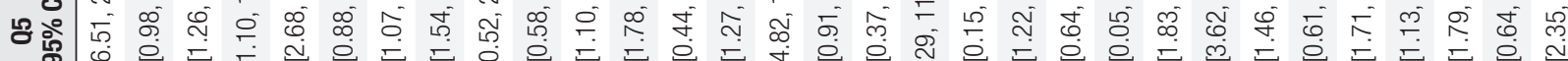

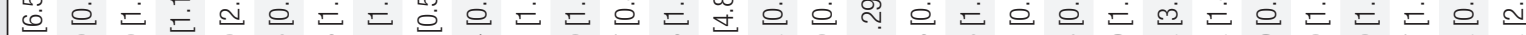
它

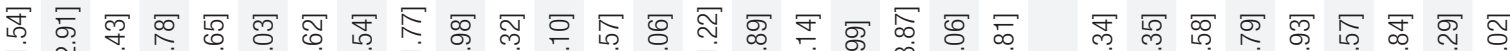

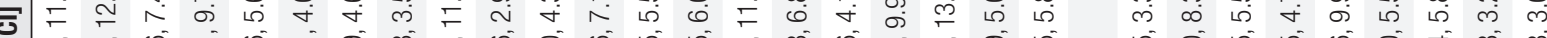

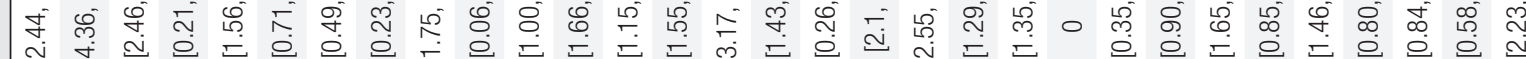

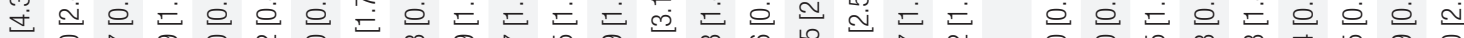
正

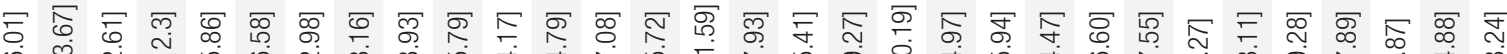

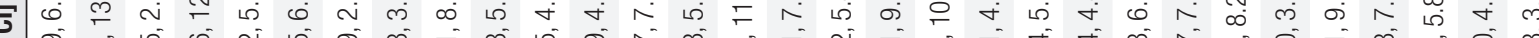

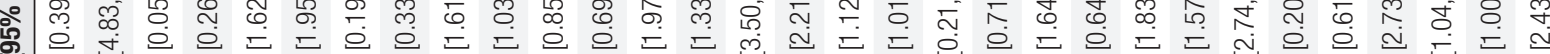

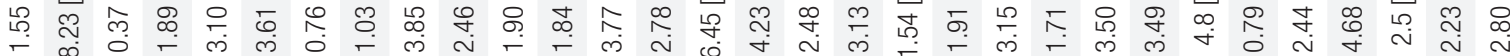

다 ळ

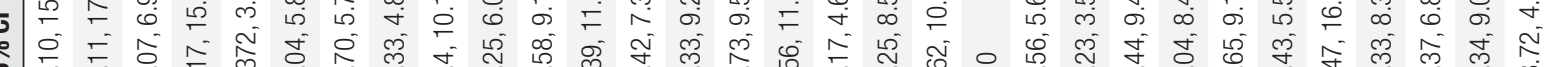

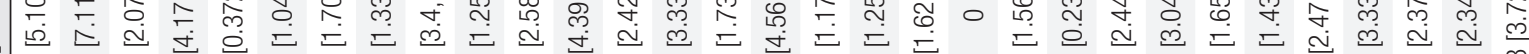

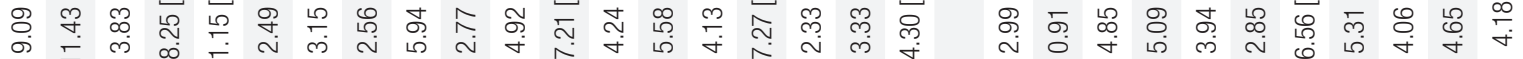

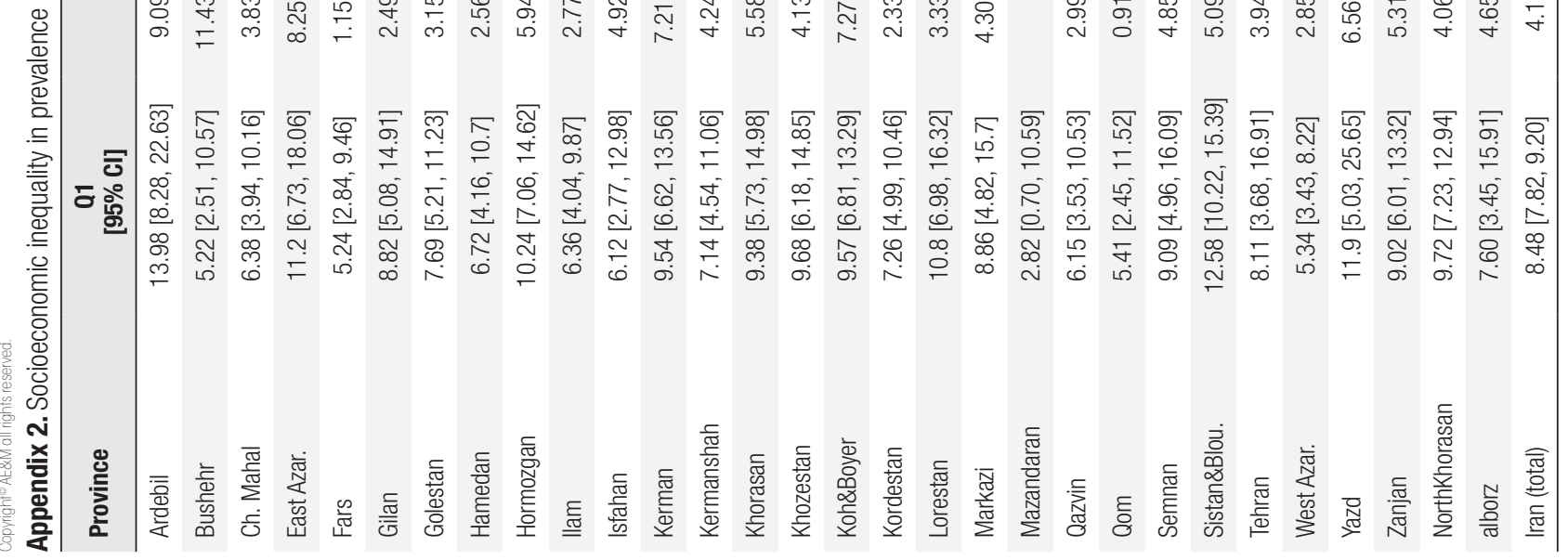

